\title{
Effects of the Shape of the Foil Corners on the Irradiation Performance of U10Mo Alloy Based Monolithic Mini-Plates
}

\section{ASME 2015 Power and Energy Conference}

Hakan Ozaltun

Pavel Medvedev

U.S. Department of Energy

National Laboratory

operated by

Battelle Energy Alliance

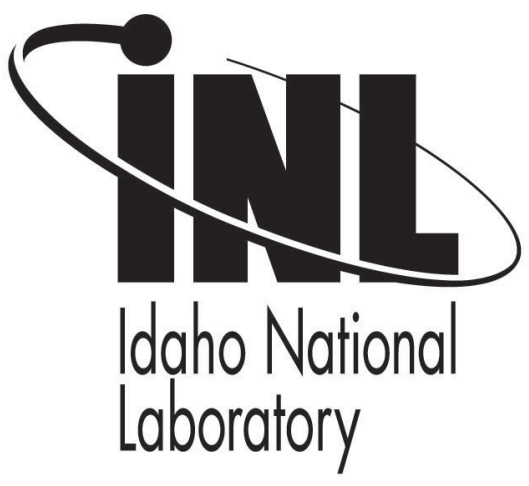

This is a preprint of a paper intended for publication in a journal or proceedings. Since changes may be made before publication, this preprint should not be cited or reproduced without permission of the author. This document was prepared as an account of work sponsored by an agency of the United States Government. Neither the United States Government nor any agency thereof, or any of their employees, makes any warranty, expressed or implied, or assumes any legal liability or responsibility for any third party's use, or the results of such use, of any information, apparatus, product or process disclosed in this report, or represents that its use by such third party would not infringe privately owned rights. The views expressed in this paper are not necessarily those of the United States Government or the sponsoring agency. 


\section{EFFECTS OF THE SHAPE OF THE FOIL CORNERS ON THE IRRADIATION PERFORMANCE OF U10MO ALLOY BASED MONOLITHIC MINI-PLATES}

\author{
Hakan Ozaltun \\ Idaho National Laboratory \\ Idaho Falls/ID - USA
}

\author{
Pavel Medvedev \\ Idaho National Laboratory \\ Idaho Falls/ID - USA
}

\begin{abstract}
Monolithic plate-type fuel is a fuel form being developed for high performance research and test reactors to minimize the use of enriched material. These fuel elements are comprised of a high density, low enrichment, U-Mo alloy based fuel foil, sandwiched between Zirconium liners and encapsulated in Aluminum cladding. The use of a high density fuel in a foil form presents a number of fabrication and operational concerns, such as: foil centering, flatness of the foil, fuel thickness variation, geometrical tilting, foil corner shape etc. To benchmark this new design, effects of various geometrical and operational variables on irradiation performance have been evaluated. As a part of these series of sensitivity studies, the shape of the foil corners were studied. To understand the effects of the corner shapes of the foil on thermo-mechanical performance of the plates, a behavioral model was developed for a selected plate from RERTR-12 experiments (Plate L1P785). Both fabrication and irradiation processes were simulated. Once the thermo-mechanical behavior the plate is understood for the nominal case, the simulations were repeated for two additional corner shapes to observe the changes in temperature, displacement and stress-strain fields. The results from the fabrication simulations indicated that the foil corners do not alter the post-fabrication stress-strain magnitudes. Furthermore, the irradiation simulations revealed that post-fabrication stresses of the foil would be relieved very quickly in operation. While, foils with chamfered and filleted corners yielded stresses with comparable magnitudes, they are slightly lower in magnitudes, and provided a more favorable mechanical response compared with the foil with sharp corners.
\end{abstract}

Keywords: Monolithic Fuel Plate, U10Mo, Irradiation, Sensitivity, Foil corners, Finite Element Analysis

$\triangle$ Corresponding Author: Email: hakan.ozaltun@inl.gov Tel: (208) 526-0274 | Fax: (208) 526-2930

\section{INTRODUCTION}

Part of Global Threat Reduction Initiative (GTRI) program, High Performance Research Reactors Fuel Development $\left(\right.$ HPRR-FD ${ }^{(1)}$ ) program has operated with the primary objective of developing the essential technologies to minimize the use of highly enriched uranium (HEU) in civilian applications. The principle vehicle by which this goal is sought is through the conversion of research and test reactors to the use of low-enriched uranium fuels (LEU, $<20 \%{ }^{235} \mathrm{U}$ ). However, lower uranium enrichment requires higher fuel densities either as dispersion fuels at high volume loading, or in a monolithic form to compensate lower fission rates. For the conversion of high performance research reactors to low enrichment Uranium fuel, U-Mo alloy based fuels in monolithic form were proposed. These plate-type fuels consist of a high uranium density, LEU foil contained within a diffusion barrier, and encapsulated within a cladding. Materials for these fuel elements are U-10Mo for the fuel foil, Zirconium for the diffusion barrier and A16061-O for the cladding. For the foil material, various alloys were evaluated and it was found that U-Mo alloys are the most promising candidate for this purpose. Molybdenum extends the stability of the cubic gamma phase and this phase is known to be stable under typical irradiation conditions. Additionally, U-Mo alloy has a low neutron capture cross-section, good irradiation behavior, and an acceptable swelling response [1] [2] [3].

Several steps involve in the fabrication process of a monolithic plate. The initial stage of the fabrication process is the preparation of coupons made of U10Mo alloy. For this, Uranium and Molybdenum feedstock is melted in an inert atmosphere and casted into thin sheets. Then, the sheets are machined or rolled to produce thin coupons. In order to control inter-diffusion phenomenon which occurs at the fuel-

(1) Formerly RERTR, Reduced Enrichment for Research and Test Reactors 
cladding interface during the irradiation process, U10Mo coupons are laminated with Zirconium diffusion barrier prior the hot rolling process. To apply Zirconium liners on each faces of the coupons, co-rolling technique is used. For this, U10Mo coupon is placed between two thin Zirconium layers (Zr-U10Mo-Zr). Then, layers are positioned in a frame made of low carbon steel. Cover plates are placed to the top and bottom of the layers; and finally, the assembly is welded before the rolling process. The sheets are hot rolled at approximately $650{ }^{\circ} \mathrm{C}$. Multiple hot rolling passes is performed to minimize occurrence of micro cracks. Typical number of hot passes is $20-40$ for the preparation of a 0.25 $0.50 \mathrm{~mm}$ thick $\mathrm{Zr}-\mathrm{U} 10 \mathrm{Mo}$ co-rolled foil. Once reduction via hot co-rolling is completed, the coupon assembly is then placed into a furnace for 45 minutes at $650{ }^{\circ} \mathrm{C}$ to reduce the residual stresses and minimize the material anisotropy. Finally, heat treated $\mathrm{Zr}-\mathrm{U} 10 \mathrm{Mo}$ co-rolled foils are removed from the rolling assembly by trimming the perimeters of coupons. The final stage of the foil preparation is to reduce the thickness of $\mathrm{Zr}-\mathrm{U} 10 \mathrm{Mo}$ co-rolled foil to its targeted value via cold rolling process. Typical thickness reduction is 0.015 $0.025 \mathrm{~mm}$ per pass. Final thickness of the co-rolled foil varies depending on the reactor application. The cold rolling process creates smoother foil surfaces and lead to more uniform foil thickness facilitating higher quality of the bonds during subsequent Hot Pressing process [4]. Finally, the co-rolled foils are encapsulated in a cladding material via Hot Isostatic Pressing (HIP), completing the fabrication process. For this, a co-rolled foil (trimmed to target dimensions prior HIP) is placed between two layers of Aluminum cladding material. These layers are subjected to a HIP procedure conducted at $560{ }^{\circ} \mathrm{C}$ and $104 \mathrm{MPa}$ for 90 minutes before being cooled to room temperature at a rate of $4.8^{\circ} \mathrm{C} / \mathrm{min}$ with diminishing the pressure as described elsewhere [5].

Once the HIP process is complete, the fuel plates have a targeted thickness of $1.397 \mathrm{~mm}$. These plates are then trimmed to their final length and width, $101.473 \mathrm{~mm} \times 25.400$ $\mathrm{mm}$, respectively. Inside the cladding, the foil and liners have a nominal thickness of $0.254 \mathrm{~mm}$ and $0.0254 \mathrm{~mm}$, respectively. Nominal dimensions for the finished product are shown in Figure 1a.

The mini-plates are then assembled into capsules made of AL6061-T6. There are 4 capsules named A, B, C and D from top to bottom, and each capsule can hold 8 mini-plates. Containing 32 mini-plates, the capsule assembly is then positioned vertically in a basket. The plates are cooled by a direct contact with the primary coolant. Even though, the plate-type fuels in monolithic form provided satisfactory irradiation results, the use of a fuel in a foil form still presents several fabrication challenges such as foil centering, flatness, thickness variation, tilting and corner shapes of the foil. These challenges raise concerns, if these parameters have implications on fuel performance. In order to understand the irradiation behavior better and to provide support for the fuel specification, this new design must be benchmarked for a number of variables via parametric studies. These include geometric variables as mentioned above, as well as operational variables such as mechanical constraint, cooling rate and thermal cycling, etc. For this work, effects of the corner shapes of the fuel on the thermo-mechanical performance of a plate were studied. For this, a selected plate from RERTR-12 test matrix was simulated for the base case (foil with chamfered corners). By using same irradiation parameter two additional corner shapes were simulated. The resulting distortions, stress-strain fields and temperature profiles were evaluated on selected locations to make a comparative assessment. Finally, a comparative evaluation was made to determine the sensitivity of the plate's performance to the shape of the foil corners.

The plate was L1P785 from RERTR-12 test matrix. This plate was irradiated at frontal neutron flux configuration (face-on orientation) in position B-5 (the bottom row of Capsule B). The plate was in $1^{\text {st }}$ slot in the Capsule B, between the coolant channels 1 and 2. This setup was shown schematically in Figure $1 b$.

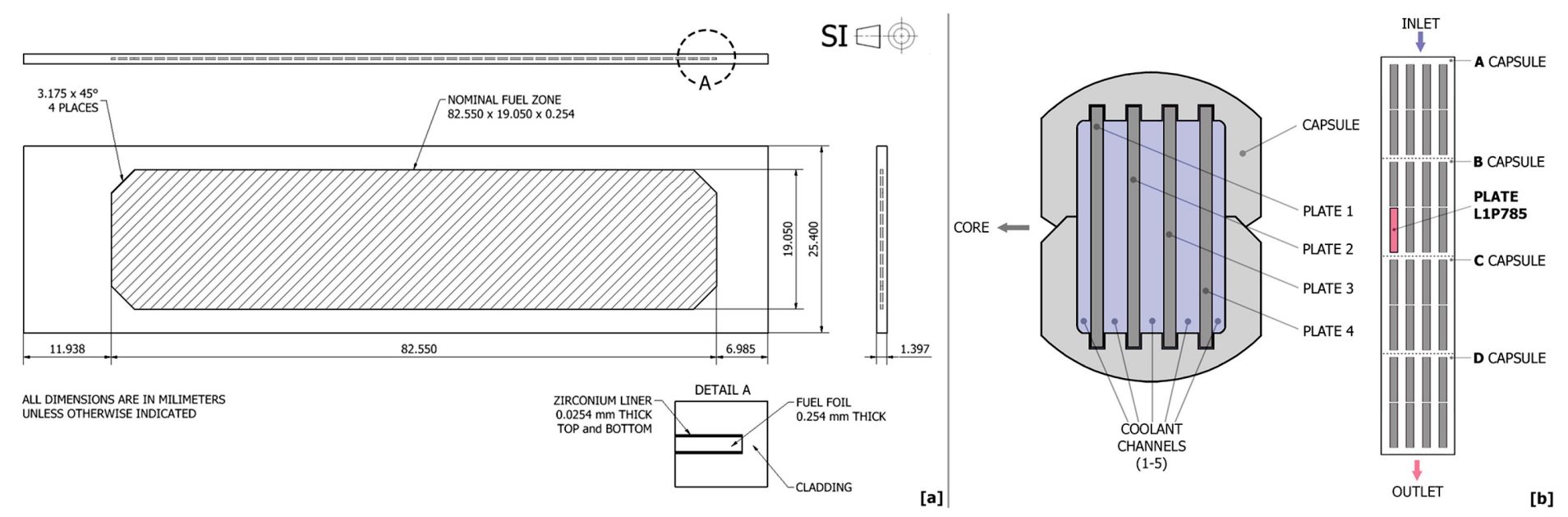

Figure 1 (a) Mini-plate dimensions that were used in the model (b) Capsule, coolant channels and position of L1P785 


\section{IRRADIATION PARAMETERS}

The plate L1P785 was irradiated in 2 cycles of RERTR-12 test matrix. Total irradiation time for the plate was 89.7 days. Effective irradiation times with respect to cycles are 50.5 days in cycle 146A; and, 39.2 days in cycle 146B.

The experimental data for the fission power density, fast neutron flux, fast neutron fluence and average fission density for these 2 cycles are summarized in Table 1 . These variables were implemented via utility subroutines accordingly. In the models, a linear interpolation was used to estimate the values between the known data points. In Figure 2, resulting models and comparisons with experimental data are shown.

Due to a frontal flux orientation, local to average ratio (L2AR) of the fission density varies with respect to spatial coordinates. Figure 3 shows the fission density L2AR in axial direction (Figure $3 a$ ), in transverse direction (Figure 3b), and actual 2D mapping with respect to spatial coordinates (Figure $3 c$ ).

It is important to note that an accurate implementation of the fission density is crucial for the fidelity of the results, as many irradiation parameters are affected by the local fission density;

Table 1 Irradiation Parameters for the plate L1P785 [6] [7]

\begin{tabular}{|c|c|c|c|c|c|c|}
\hline \multirow{2}{*}{$\begin{array}{l}\text { Irradiation } \\
\text { Cycle }\end{array}$} & \multicolumn{2}{|c|}{$\begin{array}{l}\text { Irradiation } \\
\text { Time }\end{array}$} & \multirow{2}{*}{$\begin{array}{c}\text { Fission Power } \\
\text { Density } \\
{\left[\mathrm{W} / \mathrm{cm}^{3}\right]}\end{array}$} & \multirow{2}{*}{$\begin{array}{c}\text { Average Fission } \\
\text { Density } \\
{\left[\text { fission } / \mathrm{m}^{3}\right]}\end{array}$} & \multirow{2}{*}{$\begin{array}{c}\text { Fast Neutron } \\
\text { Flux } \\
{\left[\mathrm{n} / \mathrm{m}^{2}-\mathrm{sec}\right]}\end{array}$} & \multirow{2}{*}{$\begin{array}{c}\begin{array}{c}\text { Fast Neutron } \\
\text { Fluence }\end{array} \\
{\left[\mathrm{n} / \mathrm{m}^{2}\right]}\end{array}$} \\
\hline & [days] & [hours] & & & & \\
\hline \multirow{4}{*}{$\begin{array}{c}146 \mathrm{~A} \\
50.5 \mathrm{EFPD}\end{array}$} & 0 & 0 & 42047.89 & $0.0000 \mathrm{E}+00$ & $2.861 \mathrm{E}+18$ & $0.000 \mathrm{E}+00$ \\
\hline & 16 & 384 & 38668.52 & $1.9231 \mathrm{E}+27$ & $2.819 \mathrm{E}+18$ & $3.955 E+24$ \\
\hline & 32 & 768 & 36893.53 & $3.6918 \mathrm{E}+27$ & $2.662 \mathrm{E}+18$ & $7.851 \mathrm{E}+24$ \\
\hline & 50.5 & 1212 & 34861.85 & $5.6273 \mathrm{E}+27$ & $2.593 \mathrm{E}+18$ & $1.211 \mathrm{E}+25$ \\
\hline \multirow{4}{*}{$\begin{array}{c}146 \mathrm{~B} \\
39.2 \mathrm{EFPD}\end{array}$} & 50.5 & 1212 & 31319.60 & $5.6273 \mathrm{E}+27$ & $2.298 \mathrm{E}+18$ & $1.211 \mathrm{E}+25$ \\
\hline & 68.5 & 1644 & 29073.07 & $7.2331 \mathrm{E}+27$ & $2.332 \mathrm{E}+18$ & $1.568 \mathrm{E}+25$ \\
\hline & 78.5 & 1884 & 28194.81 & $8.0774 \mathrm{E}+27$ & $2.276 \mathrm{E}+18$ & $1.770 \mathrm{E}+25$ \\
\hline & 89.7 & 2152.8 & 27226.69 & $8.9906 \mathrm{E}+27$ & $2.237 \mathrm{E}+18$ & $1.990 \mathrm{E}+25$ \\
\hline
\end{tabular}
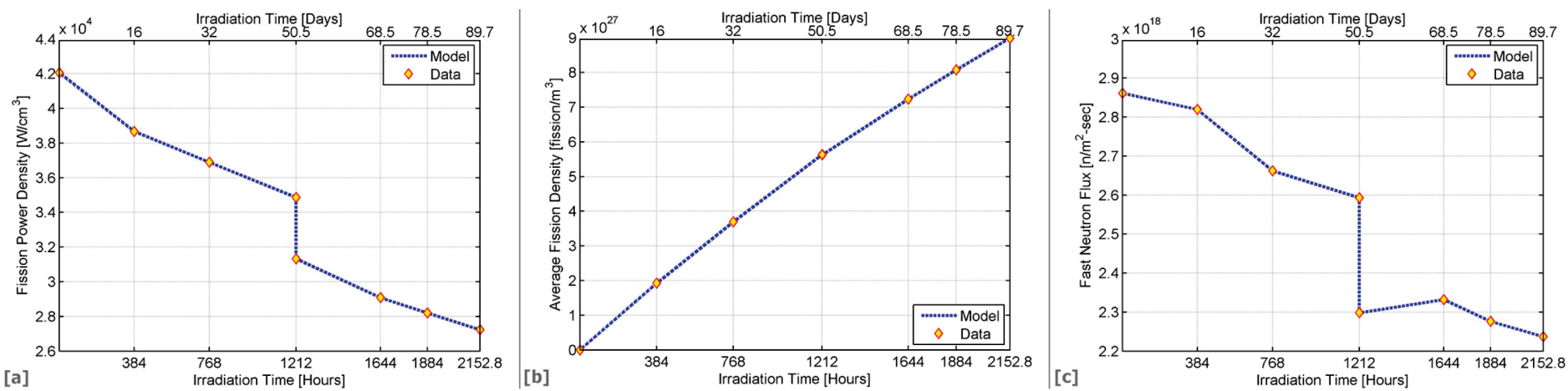

Figure 2 Irradiation Parameters (a) Fission Power Density (b) Average Fission Density (c) Fast Neutron Flux

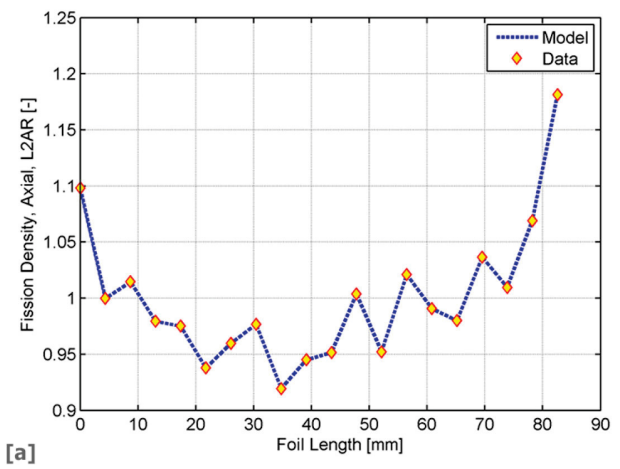

[a]

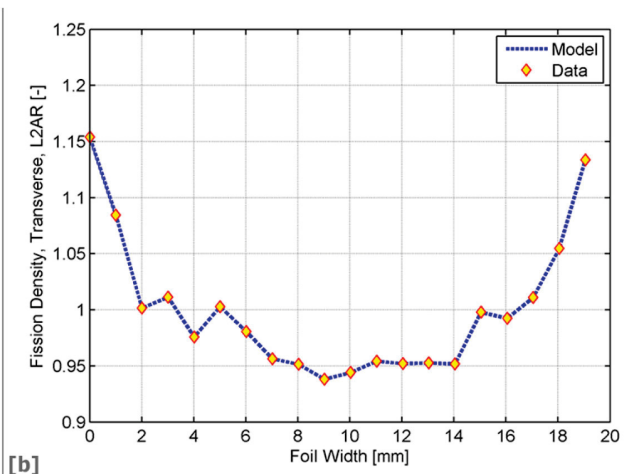

[b]

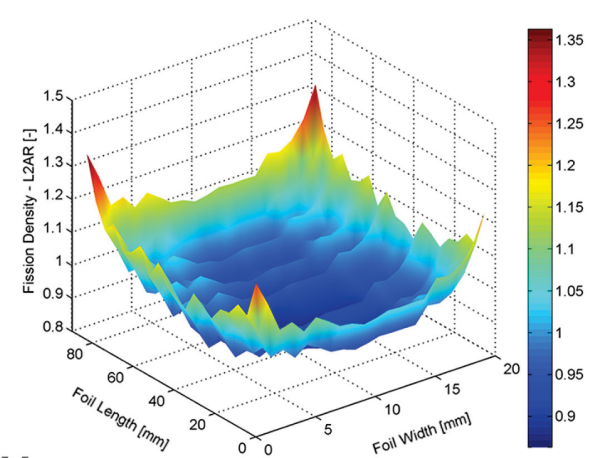

[c]

Figure 3 Fission Density, L2AR (a) Axial direction (b) Transverse direction (c) 2D field over the foil 
such as, volumetric heat generation, foil swelling, irradiation creep, conductivity degradation etc.

The average fission density in the fuel foil was constructed as a linear interpolation of ordered pairs of average fission density and time shown in Figure $2 b$. This function is called on each material point to return the value of the average fission density. The value for the local to average fission density ratio along the lengthwise and widthwise edges of the foil was implemented at twenty points, which are spaced equally from each other along those respective spatial dimensions. Linear interpolations were used to calculate L2AR between the grid points in the length and width directions. The resulting interpolation values were multiplied (bi-linear interpolation) to yield a surface mapping field of the L2AR fission density across the fuel foil as shown in Figure $3 c$. Finally, the local fission density at a given time was calculated as the product of the average fission density and the local to average fission density ratio at each material point within the fuel foil.

Volumetric heat generation rate due to fissions is shown in Figure 2a. Data for the average power density was gathered from the neutronics calculations [7] and it was implemented as a function of the irradiation time. Between the time points, a linear interpolation was used to approximate the fission power density at a specific irradiation time. The average fission power density (Figure $2 a$ ) was then multiplied by the Local to Average Ratio of the fission density (Figure $3 c$ ) to calculate the local volumetric heat generation in a specific location and a time. This procedure was repeated for the each material point at every time increments.

Shown in Figure 2c, the data for the fast neutron flux was gathered from the neutronics calculations. Similar with the heat generation rate, it was also implemented as a function of irradiation time. A linear interpolation was used to calculate the flux and fluence at a specific time for each material point. Values for the fast neutron flux were used to simulate the irradiation effects on Al6061 cladding and Zirconium liner. The irradiation effects that were considered for this work are irradiation hardening, swelling and creep.

\section{FINITE ELEMENT MODEL}

The geometric model was created by using the nominal dimensions that were shown in Figure 1. No symmetry was used as the coolant temperature increase slightly when it travels through the channel (on x-axis, length of the plate), and, coolant has different temperatures for different channels. To account these, a full model was used as shown in Figure 4.

C3D8RT element of ABAQUS, an 8-node thermally coupled brick, tri-linear displacement and temperature with reduced integration and hourglass control, was used. Chamfered edges were represented by $7 \times 7 \times 10$ nodal divisions. Equally spaced 4 layers were used to represent the thickness of the foil. Nodal divisions along the length and width directions are 174 and 42, respectively. A total number element on the foil was 29168 bricks. Equally spaced 3 layers were used to represent the thickness of the Zirconium liner. Similar with the foil, each of the Zirconium liners utilized 174 and 42 divisions along its length and width direction, respectively. This resulted 21876 hexahedral for one liner, and total 43752 hexahedral for the both liners. The thickness of the cladding material was represented by 16 layers. The nodal divisions along the length and the width directions of the cladding are 214 and 56, respectively. The total number element on the cladding was 121448. For all four parts of the plate, a mapped meshing with sweeping technique was used to match the elements and the nodal points at the interfaces. The total number of elements in the plate was 194368 hexahedral. Resulted finite element discretization of the geometry is shown in Figure 4.

It was assumed that the bonding between the foil, cladding and Zirconium liner are ideal and there are no defects present prior irradiation. It was also assumed that no interfacial delamination occurs during the irradiation. Thus, all nodal points at the interfaces were merged. The plate was modeled as free to move in all direction, except on the edges. At the longitudinal edges, only the sliding motion (along the $\mathrm{x}$-axis) was permitted. One single node on cladding corner was fixed to prevent rigid body motion.

For this work, two consecutive simulations were performed, namely, fabrication and irradiation. Irradiation simulation used the stress-strain results from the fabrication simulation as an initial state for the irradiation. Residual stress and strain fields caused by the cooling stage of the HIP process were calculated via a fully coupled, temperature-displacement simulation.

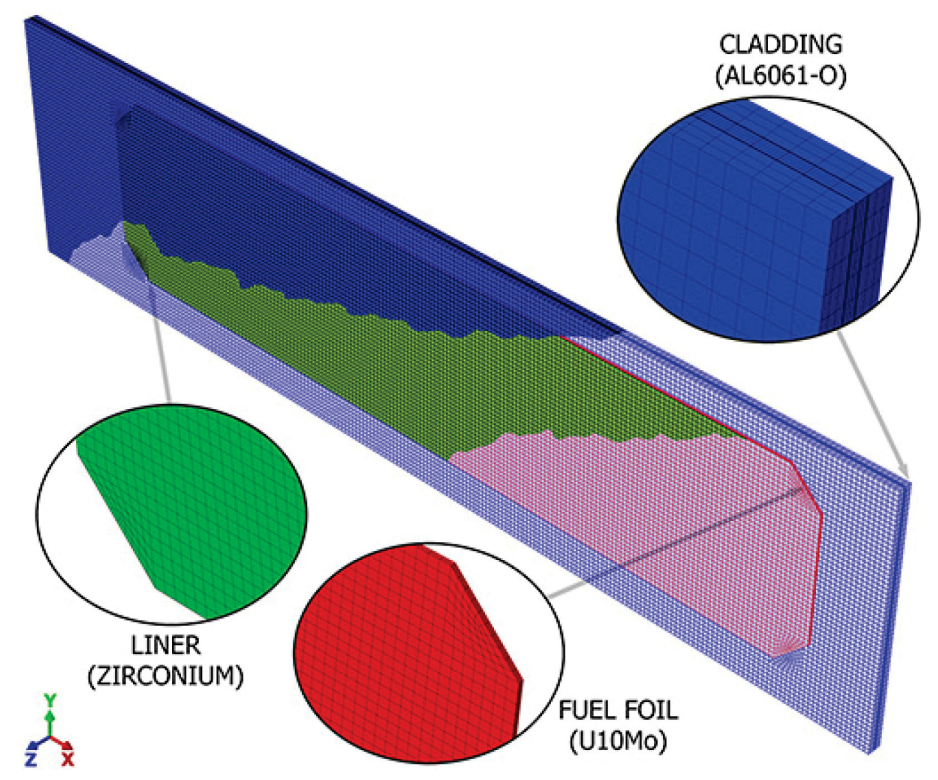

Figure 4 Geometric model and FE discretization 
Fabrication simulation was built by using a transient step of 6737 seconds with a predefined initial and a final temperature fields. The predefined temperature field was $560{ }^{\circ} \mathrm{C}$ (HIP temperature) and was uniform throughout the plate. The subsequent step introduced a room temperature as a boundary condition across the surface of the plate, and the temperature was then allowed to decrease during the transient. Cooling rate was $4.8^{\circ} \mathrm{C} / \mathrm{min}$. A single node at the volumetric center was fixed to prevent rigid body motion. Subsequent simulations used the same geometrical model and finite element mesh to for consistency. The results of this simulation were passed to the irradiation simulation to define the initial state.

Irradiation process was modeled for 2152.8 hours (89.7 days). Time history was divided into 2 sub-steps for each irradiation cycles (cycle 146A and cycle 146B). Irradiation cycle $146 \mathrm{~A}$ was simulated for 1212 hours ( 50.5 days) followed by $146 \mathrm{~B}$ for 940.8 hours (39.2 days).

To implement the field variables, ABAQUS utility subroutines were created accordingly. The USDFLD user routine was used to define the local fission density within the fuel foil with respect to the spatial coordinates and the irradiation time. This subroutine was also used to calculate the fast neutron flux and fluence for the cladding and the liner materials. Thermal conductivity degradation of the fuel foil was implemented as a function of the local fission density. It was introduced to the model via an independent field variable.

The irradiation induced creep and the models for the gaseous, solid and total swelling for the fuel foil was implemented in the user subroutine CREEP. Irradiation effects in the cladding material such as swelling strain and neutron hardening was included in this routine also.

The fission power density of the fuel foil was introduced as a body heat flux in the model. Local volumetric heat generation of the foil was calculated by using L2AR of the fission density. Heat transfer calculations between the plate surface and the primary coolant were performed by using Petukhov correlation. A film condition was created on the cladding surface and experimental coolant channel temperatures were used for the channel definition.

Plate edges along the lengthwise and widthwise directions were constrained (sliding only) to simulate the mechanical restrictions resulted by the fuel capsule restraints. A single node at the outer corner of the plate was fixed to prevent rigid body motion.

A fully coupled thermal-displacement transient solver with active swelling-creep-viscoelastic behavior was employed. An explicit-implicit integration scheme was selected for the solver. Maximum time increment per step was set to be 12 hours and maximum temperature increment per step was set to be $5{ }^{\circ} \mathrm{C}$ to avoid numerical instabilities.

\section{MATERIAL MODELS}

Material models that were used in this study are: U10Mo for the fuel, Zirconium for the liner, AL6061-O for the cladding, and light water at $2.52 \mathrm{MPa}$ for the coolant models. Material properties that were used for the model are in Appendix A.

Model for the thermal conductivity degradation of the fuel material was adapted from Hayes [8] and expressed by,

$k_{p}=k_{0} \times e^{(-2.14 \times P)}$

where $k_{0}$ is the thermal conductivity of the fully dense material, $P$ is the porosity factor (valid for $P \leq 0.3$ ) and $k_{p}$ is the thermal conductivity of the porous medium.

Porosity factor, $P$ was calculated via,

$P=\frac{\left(\Delta V / V_{0}\right)_{g}}{\left(\Delta V / V_{0}\right)_{g}+1}$

where $\left(\Delta \mathrm{V} / \mathrm{V}_{0}\right)_{\mathrm{g}}$ is swelling due to the gaseous products. The model for the gaseous swelling was adapted from [9] as,

$\left(\frac{\Delta V}{V_{0}}\right)_{g}=1.0 \cdot f_{d} \quad \begin{array}{r}f_{d} \leq 3 \times 10^{27} \\ \text { fis } / \mathrm{m}^{3}\end{array}$

$\left(\frac{\Delta V}{V_{0}}\right)_{g}=3.0+2.3 \cdot\left(f_{d}-3\right)+0.33 \cdot\left(f_{d}-3\right)^{2} \quad \begin{array}{r}f_{d}>3 \times 10^{27} \\ \text { fis } / \mathrm{m}^{3}\end{array}$

where $\left(\Delta \mathrm{V} / \mathrm{V}_{0}\right)_{\mathrm{g}}$ gaseous swelling in $(\%)$ and $f_{d}$ is local fission density in $\times 10^{27}$ (fissions $/ \mathrm{m}^{3}$ ).

Irradiation induced creep model is based on the relation given by $\operatorname{Kim}[9]$ as,

$\dot{\varepsilon}=A \cdot \sigma \cdot \dot{f}$

where, $\dot{\varepsilon}$ is creep strain rate $(1 / \mathrm{sec}), A$ is irradiation creep coefficient $\left(500 \times 10^{-25} \mathrm{~cm}^{3} / \mathrm{MPa}\right.$-fis $), \sigma$ is equivalent stress (MPa) and $\dot{f}$ is fission density rate (fissions $/ \mathrm{cm}^{3}-\mathrm{sec}$ ).

The model for the fuel meat swelling due to fission products is based on the relation given by Kim [9] as,

$$
\begin{array}{lr}
\left(\frac{\Delta V}{V_{0}}\right)_{f}=5.0 \cdot f_{d} & \begin{array}{r}
f_{d} \leq \begin{array}{r}
3 \times 10^{27} \\
\text { fis } / \mathrm{m}^{3}
\end{array} \\
\left(\frac{\Delta V}{V_{0}}\right)_{f}=15+6.3 \cdot\left(f_{d}-3\right)+0.33 \cdot\left(f_{d}-3\right)^{2}
\end{array} \\
f_{d}>3 \times 10^{27} \\
\text { fis } / \mathrm{m}^{3}
\end{array}
$$

where $\left(\Delta \mathrm{V} / \mathrm{V}_{0}\right)_{\mathrm{f}}$ total volumetric swelling of the fuel in $(\%)$, and $f_{d}$ is the local fission density in $\times 10^{27}$ (fissions $/ \mathrm{m}^{3}$ ). 


\section{COOLANT MODEL}

Models for the thermo-physical properties of the water were developed via the data reported by NIST [10]. Mathematical relations were created for the coolant at $2.52 \mathrm{MPa}$, the nominal operating pressure of ATR. Valid temperature range for the models is $1-100{ }^{\circ} \mathrm{C}$. In the models, $T$ is in ${ }^{\circ} \mathrm{C}$.

Density $\left(\mathrm{kg} / \mathrm{m}^{3}\right)$ was defined according to

$\rho=1.46 \times 10^{-5} \cdot T^{3}-5.664 \times 10^{-3} \cdot T^{2}+3.318 \times 10^{-3} \cdot T+1001$

The model for the specific heat $(\mathrm{J} / \mathrm{kg}-\mathrm{K})$ is

$C_{p}=2.462 \times 10^{-6} \cdot T^{4}-6.120 \times 10^{-4} \cdot T^{3}+6.169 \times 10^{-2} \cdot T^{2}-$

$$
2.459 \cdot T+4206
$$

Thermal diffusivity model $\left(\mathrm{m}^{2} / \mathrm{sec}\right)$ is

$\alpha=-2.068 \times 10^{-12} \cdot T^{2}+5.562 \times 10^{-10} \cdot T+1.334 \times 10^{-7}$

The model for thermal conductivity $(\mathrm{W} / \mathrm{m}-\mathrm{K})$ is

$k=-9.565 \times 10^{-6} \cdot T^{2}+2.147 \times 10^{-3} \cdot T+0.5609$

Kinematic viscosity $\left(\mathrm{m}^{2} / \mathrm{sec}\right)$ is

$$
\begin{aligned}
v= & 3.009 \times 10^{-14} \cdot T^{4}-8.433 \times 10^{-12} \cdot T^{3}+9.291 \times 10^{-10} \cdot T^{2}- \\
& 5.321 \times 10^{-8} \cdot T+1.758 \times 10^{-6}
\end{aligned}
$$

Dynamic viscosity $(\mathrm{Pa}-\mathrm{s})$ is

$$
\begin{aligned}
\mu= & 2.986 \times 10^{-11} \cdot T^{4}-8.382 \times 10^{-9} \cdot T^{3}+9.259 \times 10^{-7} \cdot T^{2}- \\
& 5.332 \times 10^{-5} \cdot T+0.00176
\end{aligned}
$$

The model for Prandtl Number is

$$
\begin{aligned}
\operatorname{Pr}= & 2.632 \times 10^{-7} \cdot T^{4}-7.336 \times 10^{-5} \cdot T^{3}+7.970 \times 10^{-3} \cdot T^{2}- \\
& 0.4396 \cdot T+13.13
\end{aligned}
$$

Reynolds Number was calculated according to

$$
\operatorname{Re}=\frac{\rho \cdot v \cdot D_{H}}{\mu}
$$

Where, $v$ is velocity and $D_{H}$ is hydraulic diameter. Coolant velocities are, $14.0 \mathrm{~m} / \mathrm{sec}$ and $10.8 \mathrm{~m} / \mathrm{sec}$ for inner and outer channels, respectively. Hydraulic diameter $\left(D_{H}\right)$ is

$$
D_{H}=4 A / P
$$

where $A$ is the cross sectional area and $P$ is the wetted perimeter of the cross-section.
For L1P785 plate in position B-5, the channel widths are $1.4986 \mathrm{~mm}$ for the outer channel (Channel 1). The inner channel (Channel 2) is $2.3876 \mathrm{~mm}$ wide. The channel length is $22.555 \mathrm{~mm}$ for the both channels.

Nusselt number was calculated by using Petukhov-Gnielinski correlation [11]. For a fully developed turbulent and transition flow $(\operatorname{Re}>2300)$, the Nusselt number is given by

$$
N u=\frac{\left(\frac{f}{8}\right) \cdot(\operatorname{Re}-1000) \cdot \operatorname{Pr}}{1+12.7 \cdot\left(\frac{f}{8}\right)^{1 / 2} \cdot\left(\operatorname{Pr}^{2 / 3}-1\right)}
$$

Where, Pr is the Prandtl number $(0.5 \leq \operatorname{Pr} \leq 2000)$, $\operatorname{Re}$ is the Reynolds number $\left(3000<\operatorname{Re}<5 \times 10^{6}\right)$ and $f$ is the friction factor from the first Petukhov equation. The friction factor was calculated as,

$$
f=\left(\frac{1}{0.790 \cdot \ln (R e)-1.64}\right)^{2}
$$

Finally, the heat transfer coefficient was calculated by

$$
h=\frac{k}{D_{H}} \cdot N u
$$

where, $h$ is heat transfer coefficient $\left(\mathrm{W} / \mathrm{m}^{2}-\mathrm{K}\right), k$ is thermal conductivity $(\mathrm{W} / \mathrm{m}-\mathrm{K}), D_{H}$ is hydraulic diameter $(\mathrm{m}), N u$ is the Nusselt Number. Resulted heat transfer coefficient is shown in Figure 5 .

The heat transfer between the coolant and the plate surface was simulated by creating a surface interaction, which defines a film condition at the plate surfaces. Surface film condition was created by using the reported coolant temperatures [12] and calculated heat transfer coefficients.

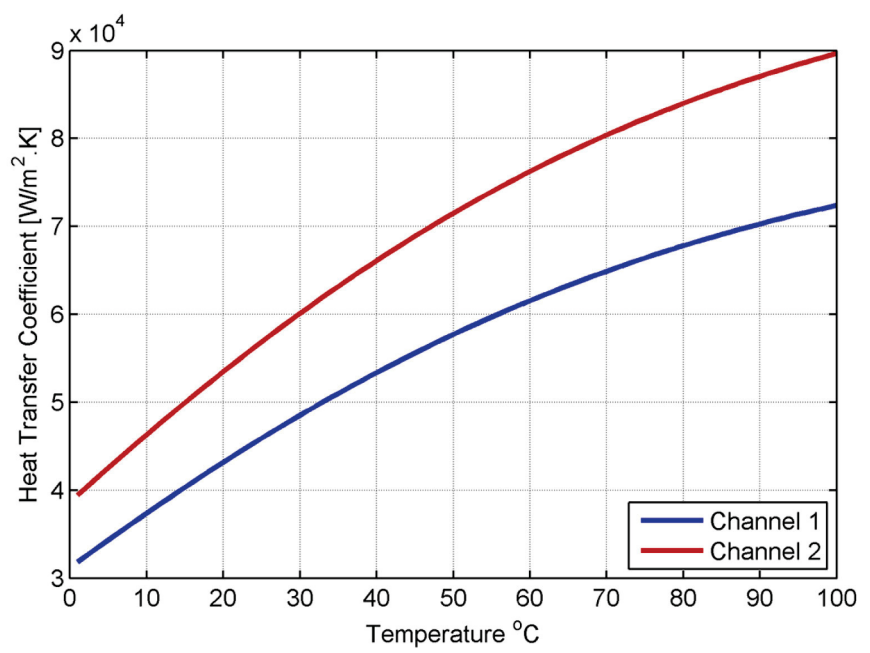

Figure 5 Heat transfer coefficient for the coolant channels 


\section{RESULTS AND DISCUSSIONS}

Residual stresses due to the fabrication process are discussed elsewhere [13] [14] [15] and will not be presented again.

\subsection{Temperature fields}

The plate L1P785 was simulated for 89.7 days (cycle 146A for 50.5 days, cycle $146 \mathrm{~B}$ for 39.2 days). The EOL (end of the cycle 146B) temperature fields are shown in Figure 6. The results are for the end of the irradiation, where the plates are at power $(27226.69$ [W/cm3]), just before the shutdown.

The temperature fields of the foil at the interface and at the centerline are shown in Figure $6 b$ and Figure $6 a$, respectively.
The peak foil temperatures were found to be at the outlet side, where the fission densities are the highest. The simulations indicated that the peak foil temperatures are $145.24^{\circ} \mathrm{C}(418.39$ $\mathrm{K})$ at the foil-Zr liner interface (Figure $6 a$ ), and $215.75{ }^{\circ} \mathrm{C}$ $(488.90 \mathrm{~K})$ at the fuel centerline (Figure $6 b$ ). Located around the perimeter of the foil, the minimum foil temperature was calculated to be $82.14{ }^{\circ} \mathrm{C}(355.30 \mathrm{~K})$.

The temperature fields in the cladding surface and at the cladding-Zirconium liner interface are shown in Figure $6 c$ and Figure $6 d$, respectively. From the figures, the peak temperature for the cladding is $111.58{ }^{\circ} \mathrm{C}(412.80 \mathrm{~K})$ at the interface with Zirconium liner, and $126.67^{\circ} \mathrm{C}(399.82 \mathrm{~K})$ at the plate surface. These peaks are closer to the outlet side. The lowest cladding temperature is $61.99{ }^{\circ} \mathrm{C}(335.14 \mathrm{~K})$.

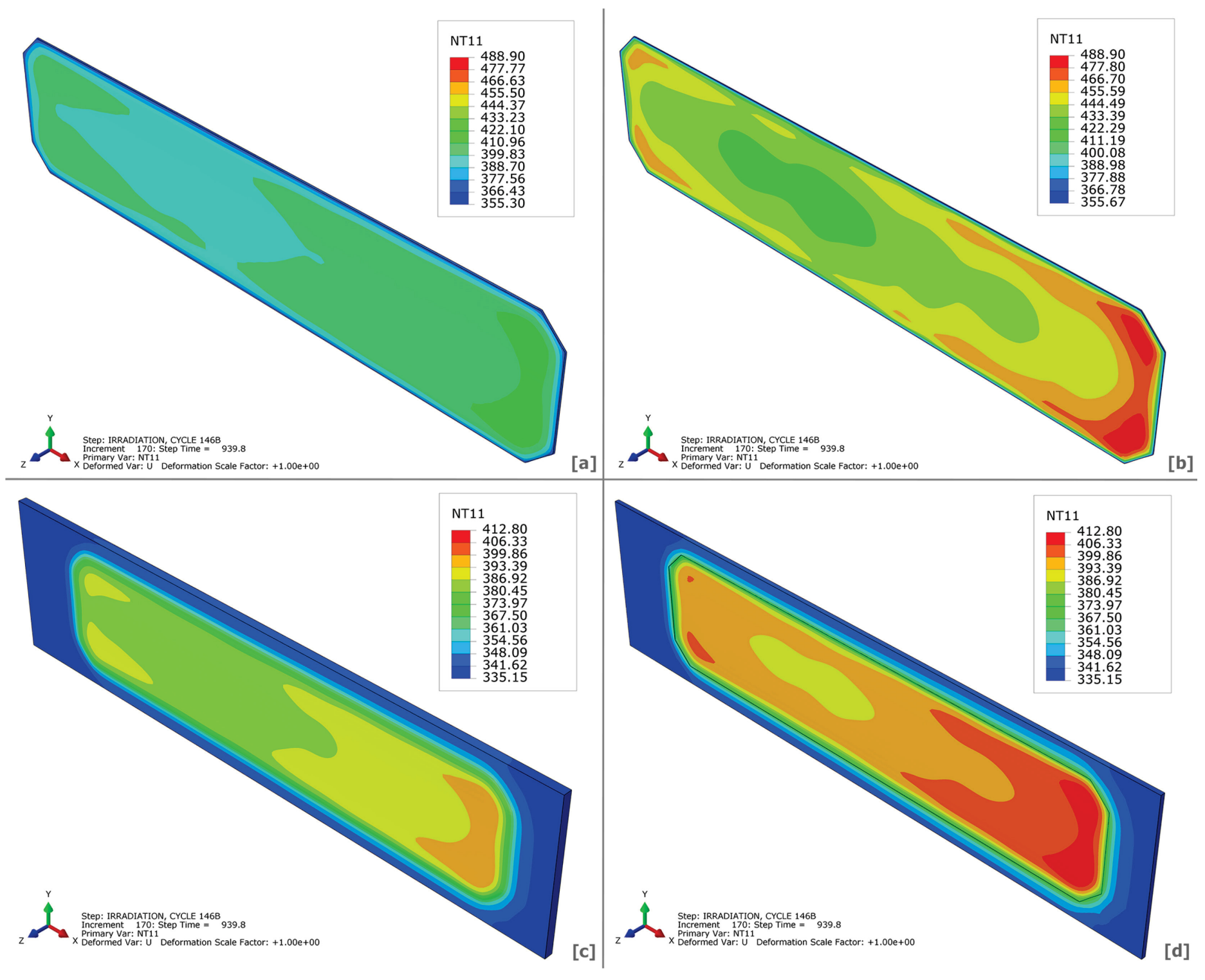

Figure 6 Temperature [K] fields, End of irradiation, (end of cycle 146B, 89.7 days, at 27226.69 [W/cm3]), contours are showing (a) Foil temperature $\left[{ }^{\circ} \mathrm{K}\right]$ at the interface (b) Foil temperature $\left[{ }^{\circ} \mathrm{K}\right]$ at the center line (c) Cladding temperature $\left[{ }^{\circ} \mathrm{K}\right]$ at the surface (d) Cladding temperature $\left[{ }^{\circ} \mathrm{K}\right]$ at the interface 


\subsection{Swelling, creep and displacement fields}

The peak fission density in the foil reaches to $1.12 \times 10^{28}$ [fis $/ \mathrm{m} 3$ ] with $1.250 \mathrm{~L} 2 \mathrm{AR}$ at the outlet side as seen in Figure $7 a$. The calculated swelling strain due to gaseous products in the foil is shown in Figure $7 b$. From the figure, the minimum gaseous swelling is $2159 \%$. Reaching to its peak closer to the outlet side, the maximum gaseous swelling is $44.38 \%$.

The large gaseous swelling has implications on the integrity of the fuel. It is shown that the gaseous swelling has a critical breakaway value and can be used to predict a failure [16]. It was formulated that when the gaseous swelling approaches $33.3 \%$, the bubbles touch neighboring bubbles in a randomly arranged configuration, assisting interconnection of the pores, and thus, facilitating escape of the gaseous products to the surface. It is also reported that as an upper limit, 30\% peak gaseous swelling is often observed [16] [17]. By using this information, it may be claimed that if the gaseous swelling reaches $30 \%$ integrity may become critical, and gaseous swelling magnitudes above $33.3 \%$ leads to a breakaway failure. In Figure $7 b$, it is shown that the perimeter of the foil has a gaseous swelling of $30 \%$ and more. Especially outlet side of the plate, a large portion of the fuel reaches to a failure point, induced by a breakaway swelling. To reveal the susceptible regions to the breakaway failure, a detail view is given. In the figure, gaseous swelling magnitudes higher than $33.3 \%$ are shown in red.

A large irradiation induced creep strain was calculated for U10Mo fuel, as shown in Figure 7c. The minimum creep strain was $31.1 \%$ at the mid-section of the foil. The larger

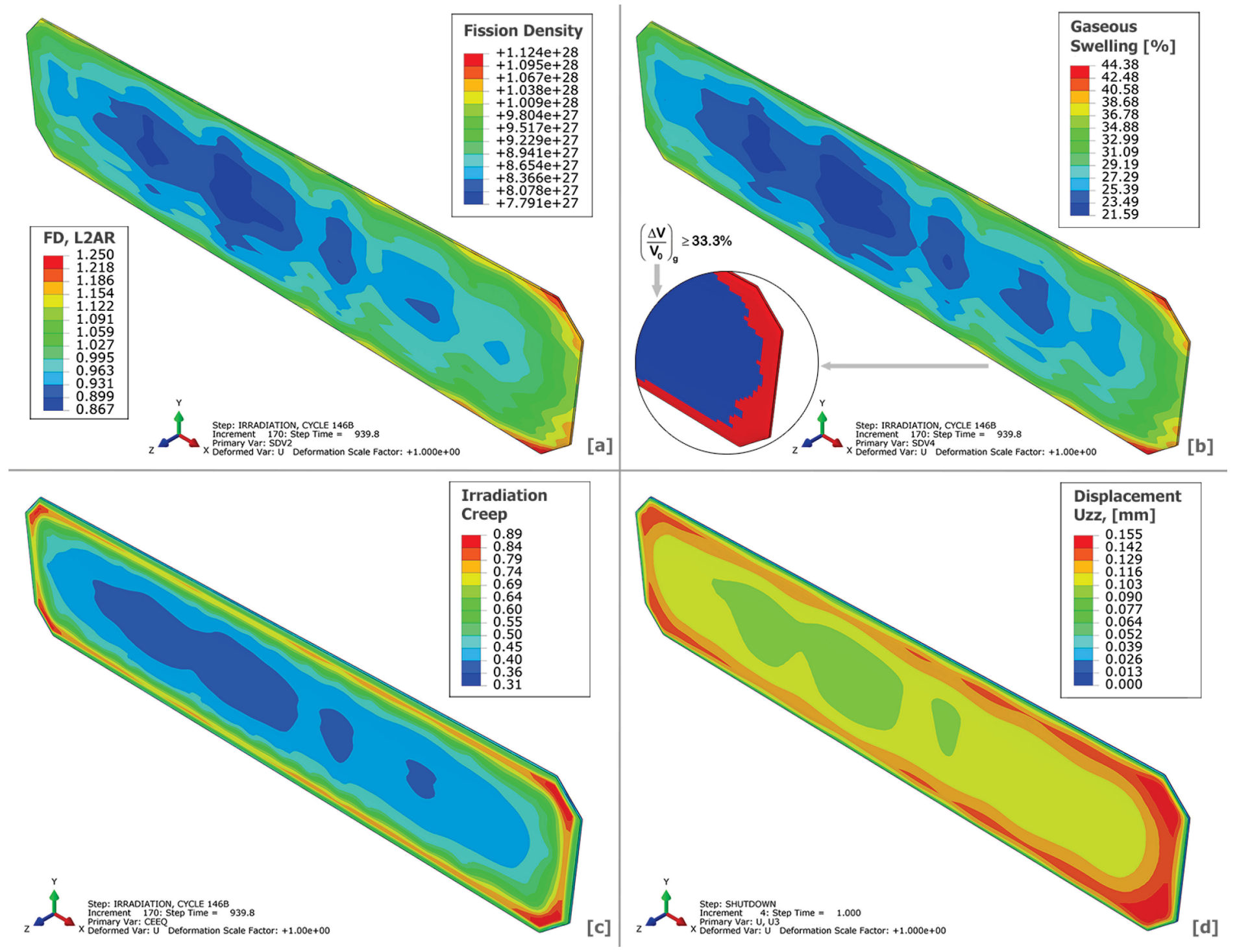

Figure 7 Contour plots for the foil at the end of the irradiation process

(a) Local fission density [fis $/ \mathrm{m}^{3}$ ] and L2AR (b) Gaseous swelling [\%] and regions with $33.3 \%$ and more gaseous swelling (c) Irradiation induced creep strain [-] in the foil (d) Total displacement [mm] of the foil in the thickness direction, bulging 
material movement was observed around the perimeter of the foil. This is caused by the external constraints created by the cladding material. The peak creep strain was computed to be $89.9 \%$ and they are closer to the fuel corners.

The displacement profile in the thickness direction is shown in Figure $7 d$. The peak growth is $0.310 \mathrm{~mm}(0.155 \mathrm{~mm}$ with respect to the centerline). This corresponds to approximately $120 \%$ peak swelling in the fuel. These peak displacements were at the bottom of the plate (i.e. outlet side). Other regions of large displacements were observed for the foil perimeter. Even though the swelling is isotropic, the fuel displacement is primarily in the thickness direction. Displacements in the length and the width directions of the fuel are little or none.

\subsection{Stress fields}

Stress fields for the foil, cladding and Zr-liner are shown in Figure 8. Equivalent stresses for the fuel foil at the end of the irradiation (end of the cycle 146B, the plate still at power for 27226.69 W/ $\mathrm{cm}^{3}$ ) is given in Figure $8 a$. The results show that the stresses during operation in the fuel foil are negligible. A closer evaluation of the results for the stress transient has indicated that the fabrication induced stresses are relieved very quickly in the reactor, and the fuel foil would be essentially stress-free during irradiation. However, the residual stresses would develop at reactor shutdown. As seen in Figure 8b, a peak equivalent stresses of $111 \mathrm{MPa}$ in a localized regions are created at shutdown. The previous simulations of different

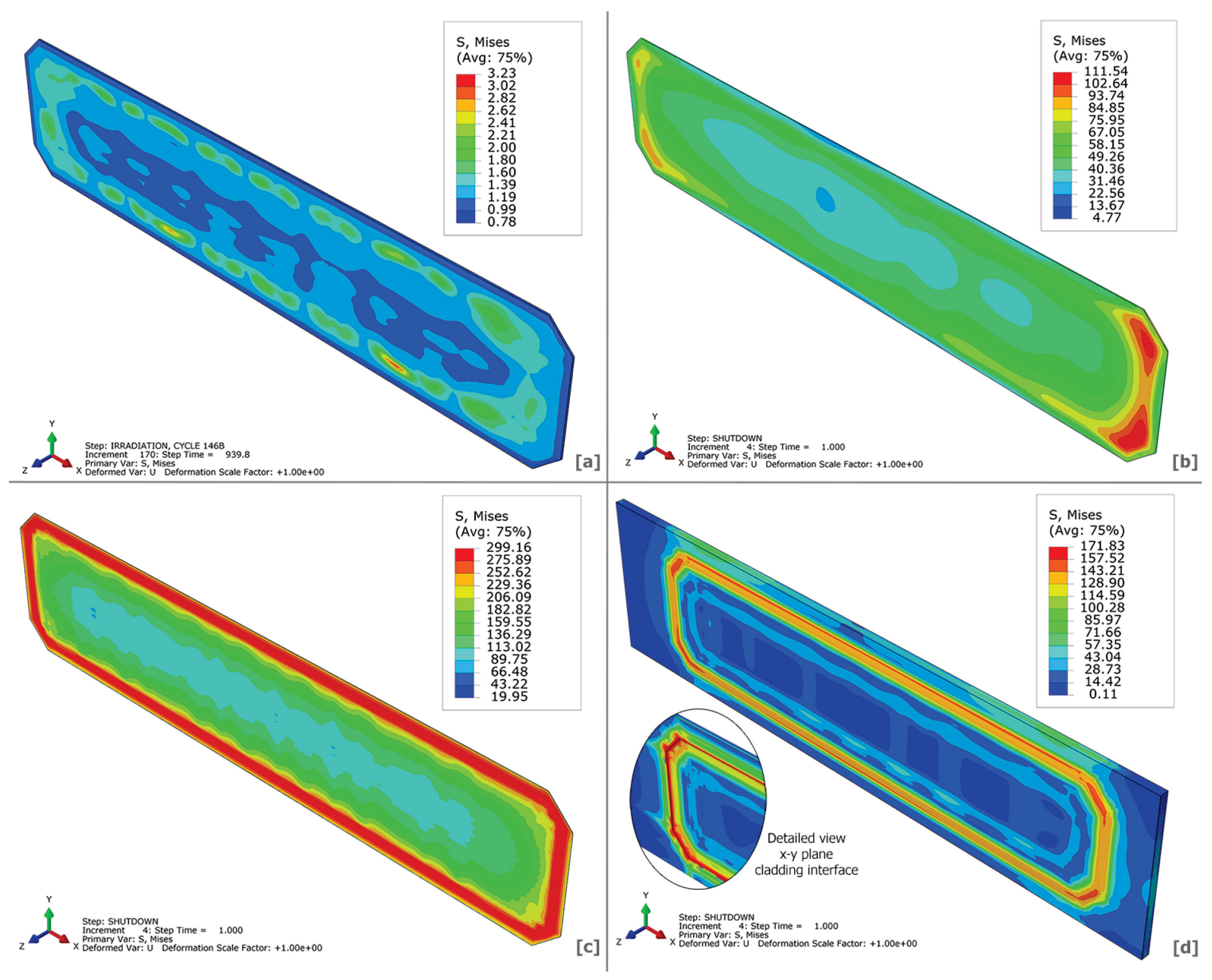

Figure 8 Equivalent stress [MPa] fields for the foil and the cladding, contours are showing (a) Foil, end of irradiation, at power (89.7 days, at $\left.27226.69\left[\mathrm{~W} / \mathrm{cm}^{3}\right]\right)$ (b) Foil, end of shutdown (c) Zirconium liner, end of irradiation, at power (89.7 days, at $\left.27226.69\left[\mathrm{~W} / \mathrm{cm}^{3}\right]\right)$ (d) Cladding, end of shutdown 
RERTR plates [14] [15] have shown that higher operational temperatures would subsequently cause higher residual stresses at shutdown. This observation is especially meaningful, if the material degradation is extensive, such as the presence of a high porosity in the fuel foil. In such case, the fuel foil could become exceedingly susceptible to the shutdown stresses. It is worth to mention that the shutdown induced residual stresses and material degradation together may be used to suggest a failure mode as discussed previously elsewhere [18].

Prior irradiation, Zr-liner material has a residual stress of 344 $\mathrm{MPa}$, induced by the fabrication process. The magnitude of this stress decreases slightly during the operation. At shutdown, Zr-liner has an equivalent stress of approximately $300 \mathrm{MPa}$ as seen in Figure $8 \mathrm{c}$. This reduction is due to the relaxation of the foil by the irradiation creep and thermal creep in $\mathrm{Zr}$-liner material.

Unlike the foil and liner materials, magnitude of the stresses in the cladding material increase during irradiation. Figure $8 d$ shows that the magnitude if the equivalent stresses in the cladding material grows to approximately $170 \mathrm{MPa}$ during the irradiation process. This increase is as a result of an irradiation hardening by the fast neutrons. Additional stresses are also formed by the cladding displacements caused by the volumetric swelling of the foil.

\subsection{Case Studies: Effects of foil corner shape}

In this section, sensitivity to the corner shapes of the foil and their effects on the thermo-mechanical performance were evaluated. For this, the plate was simulated for two additional corner shapes by using the same irradiation parameters. All geometric dimensions were kept same with those given in Figure la, except the shape of the corners. The corner shapes that were considered were Chamfer $\left(3.175 \mathrm{~mm} \mathrm{x} 45^{\circ}\right)$, Fillet (R $3.175 \mathrm{~mm}$ ) and Sharp $\left(90^{\circ}\right)$. For each corner shape, the resulting distortion, stress-strain and temperature profiles were evaluated on the selected locations.

It is important to note that the L2AR reaches to roughly 1.4 for the design with sharp corners as seen in Figure 3c. Obviously, the higher L2AR yields higher local fission densities around the corners. This consequently produces a larger volumetric

Table 2 Effects of the corner shapes on the peak magnitudes: Stress, displacement and temperature

\begin{tabular}{ccccc}
\hline $\begin{array}{c}\text { Corner } \\
\text { shape }\end{array}$ & $\begin{array}{c}\text { Foil } \\
\text { stress }\end{array}$ & $\begin{array}{c}\text { Foil } \\
\text { swelling }\end{array}$ & $\begin{array}{c}\text { Foil } \\
\text { temperature }\end{array}$ & $\begin{array}{c}\text { Plate } \\
\text { thickness }\end{array}$ \\
\hline & {$[\mathrm{MPa}]$} & {$[\mathrm{mm}]$} & {$\left[{ }^{\circ} \mathrm{C}\right]$} & {$[\mathrm{mm}]$} \\
\hline Chamfer & 80.59 & 0.2606 & 184.55 & 1.660 \\
Fillet & 83.53 & 0.2708 & 184.65 & 1.669 \\
Sharp & 88.46 & 0.2818 & 185.35 & 1.681 \\
\hline
\end{tabular}
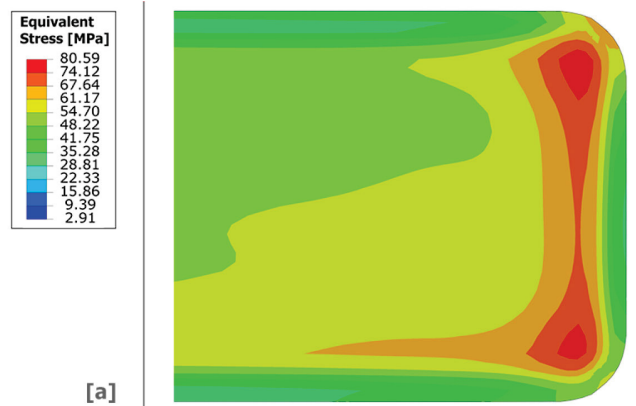
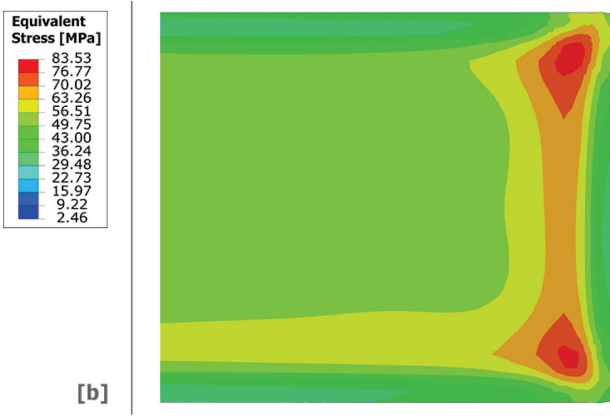

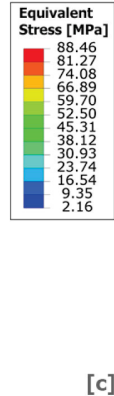

Figure 9 Equivalent stress fields for different designs with various foil corner shapes. Showing the foil:

(a) Corner-chamfered (b) Corner-filleted (c) Sharp corners
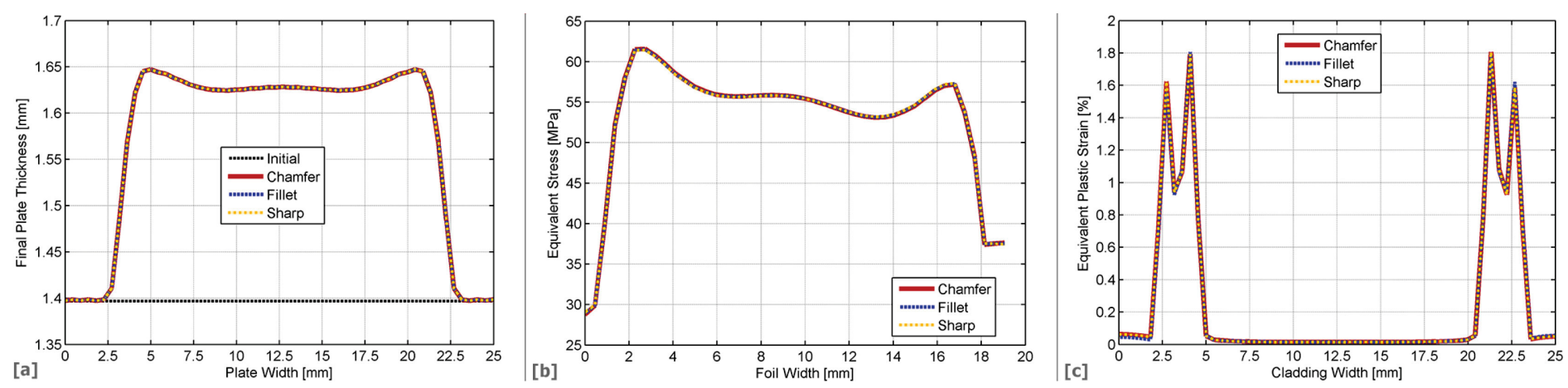

Figure 10 Mid-section evaluation, showing (a) Final plate thickness and displacement profile (b) Equivalent stress profile for the Foil (c) Equivalent plastic strain for the Cladding 
swelling strain and thickness increase, higher porosity and conductivity degradation, more heat generation and higher local temperature etc. Because the thermal and structural simulations are fully coupled, the final temperatures and resulting shutdown stresses increase even further with an increasing thickness.

Initially the sensitivity simulations were performed by using the reported L2ARs, which varied with respect to spatial coordinates. In this case, the foil design with sharp corners led to higher magnitudes of swelling, final thickness, temperature, shutdown stress, porosity, conductivity degradation etc. This implied that if the L2AR varies and the resulting fission densities are higher; then, the design with sharp corners would be the least preferred design from a mechanical perspective.

To investigate just the geometric effects, additional simulations were performed. For this, a constant fission density was used throughout the fuel foil to minimize the artificial effects of peak fission densities created by the extra fuel materials at the corners. This was achieved by setting the L2AR to 1, which essentially leads to use of average fission density for the entire foil.

Table 2 lists the peak magnitudes of the stress, foil swelling, temperature and final plate thickness. The peak stresses are slightly lower for the design with chamfered corners. The design with the sharp corners has the largest shutdown induced residual stresses. Similarly, sharp-corner foil case has slightly higher bulging at the corners. Furthermore, the resulting peak plate thickness is also slightly higher for the design with the sharp corners.

In Figure 9, location of the peak stresses are shown. Even though, all three cases have similar stress patterns with the peaks that are located closer to the corners, the magnitudes of the peak stresses are approximately $10 \%$ higher for the design with the sharp corners.

It is difficult to propose exact stresses-strain magnitudes that would eventually facilitate a failure, as the irradiated material properties have not been studied extensively. However, it would be still acceptable to claim that the design with sharp corners would be the least favorable design, as it has higher stress-displacement magnitudes, compared with the designs with filleted or chamfered corners. High stress magnitudes may be important, especially at shutdown stage, as the fuel foil becomes more susceptible to the external loads, if a sufficient material degradation such as high porosity is present. Obviously, higher shutdown induced stress may act a failure facilitator as discussed previously [18].

Finally, Figure 10 presents the results for displacement, stress and strain profiles at the mid-section of the plate. Even though mid-section of the plate is far from the corners and it is less likely that the geometric variations of corners would have implications in these areas, results were evaluated at the midsection for completeness. The graphs in Figure 10 indicate that the results at the mid-plane are not affected by the corner shapes. Additionally, the results from the mid-plane of the plate cannot be used to explain the overall behavior.

\section{CONCLUSIONS}

In order to provide support for the fuel specification, the platetype fuel design has been evaluated for a number of variables via parametric studies to ease the fabrication and operational constraints. In this work, as a part of a series of sensitivity studies, implications of the foil's corner on the thermomechanical performance of the plates were studied. A behavioral model for a selected plate from RERTR-12 experiments (Plate L1P785) was developed.

First, overall behavior of this experimental plate was benchmarked by evaluating the operational performance such as temperature, displacement, stress-strain fields etc. Even though the irradiation simulations showed that the postfabrication stresses of the foil would be relieved very quickly during the operation, a residual stresses would still develop at the shutdown stage. Combined with a material degradation caused by a large porosity, these shutdown induced stresses may be a possible failure mode for the plates.

The simulations were then repeated for additional corner shapes to observe the behavioral changes in the temperature, displacement and the stress-strain fields. For this, two sets of simulations were performed. While the first set utilized a variable $\mathrm{L} 2 \mathrm{AR}$, the second set used a uniform fission density.

First set used a variable L2AR (variable fission density). The results indicated that the foil design with sharp corners produces higher peak values due to additional fission densities around the corners.

The second set of simulations used uniform fission densities in the fuel to see just the geometric effects. The results of these simulations indicated that the designs with chamfered and filleted corners produce stresses and displacements in comparable magnitudes, and they are slightly lower in magnitudes comparing with those for the design with the sharp corners.

From thermo-mechanical perspective, the design of the foil with the sharp corners was found to be least favorable. The corner-chamfered and corner-filleted foil designs are comparable and produce more favorable results.

\section{ACKNOWLEDGMENTS}

This work was supported in part by an allocation of computing time from High Performance Computing facilities of Idaho National Laboratory. 


\section{US DOE DISCLAIMER}

This manuscript has been authored under Contract DE-AC0705ID14517 with the US Department of Energy. The US Government retains and the publisher, by accepting the article for publication, acknowledges that the US Government retains a nonexclusive, paid-up, irrevocable, world-wide license to publish or reproduce the published form of this manuscript, or allow others to do so, for US Government purposes.

This information was prepared as an account of work sponsored by an agency of the U.S. Government. Neither the U.S. Government nor any agency thereof, nor any of their employees, makes any warranty, express or implied, or assumes any legal liability or responsibility for the accuracy, completeness, or usefulness of any information, apparatus, product, or process disclosed, or represents that its use would not infringe privately owned rights. References herein to any specific commercial product, process, or service by trade name, trademark, manufacturer, or otherwise, does not necessarily constitute or imply its endorsement, recommendation, or favoring by the U.S. Government or any agency thereof. The views and opinions of authors expressed herein do not necessarily state or reflect those of the U.S. Government or any agency thereof.

\section{REFERENCES}

[1] J. L. Snelgrove, G. L. Hofman and M. K. Meyer, "Development of very high density low-enriched Uranium fuels," J. Nucl. Eng. Des., vol. 178, p. 119-12, 1997.

[2] M. K. Meyer, G. L. Hofman, S. L. Hayes and C. R. Clark, "Low temperature irradiation behavior of U-Mo alloy dispersion fuels," J. Nucl. Mater., vol. 304, pp. 221236, 2002.

[3] J. M. Park, K. H. Kim, C. K. Kim, M. K. Meyer, G. L. Hofman and R. V. Strain, "The irradiation behavior of atomized U-Mo alloy fuels at high temperature," J. Met. Mater. Int., vol. 7, no. 2, p. 151-157, 2001.

[4] G. A. Moore and M. C. Marshall, "INL/EXT 10-17774: Co-Rolled U10Mo/Zirconium Barrier Layer Monolithic Fuel Foil Fabrication Process," Idaho National Laboratory, Idaho Falls, 2010.

[5] J. F. Jue, H. P. Blair, R. C. Curtis, A. M. Glenn and D. K. Dennis, "Fabrication of monolithic RERTR fuels by Hot Isostatic Pressing," J. Nucl. Technol, vol. 172, no. 2, pp. 204-210, 2010.

[6] M. A. Lillo and G. S. Chang, "ECAR-1394: RERTR-12-3 Projected Physics Analysis Results for Use in Thermal and Oxide Growth Evaluations," Idaho National Laboratory, Idaho Falls, 2012.

[7] M. A. Lillo, "ECAR-1832: MCNP-Calculated Fission Power Gradients for RERTR-12 Mini-Plates Irradiated in
ATR," Idaho National Laboratory, Idaho Falls, 2012.

[8] S. L. Hayes, G. L. Hofman, M. K. Meyer and J. Rest, "Modeling of high density of U-Mo dispersion fuel plate performance," in 24th International Meeting on Reduced Enrichment for Research and Test Reactors (RERTR), San Carlos de Bariloche, Argentina, 2002.

[9] Y. S. Kim, G. L. Hofman, J. S. Cheon, A. B. Robinson and D. M. Wachs, "Fission induced swelling and creep of U-Mo alloy fuel," Journal of Nuclear Materials, vol. 437, pp. 37-46, 2013.

[10] E. W. Lemmon, M. L. Huber and M. O. McLinden, "NIST Standard Reference Database 23: Reference Fluid Thermodynamic and Transport Properties - REFPROP, Version 9.0, NIST, Standard Reference Data Program," National Institute of Standards and Technology, Gaithersburg, MD, 2010.

[11] F. P. Incropera and D. P. DeWitt, Introduction to Heat Transfer, Fourth ed., New York, NY: Wiley, ISBN: 0471386499, 2001, pp. 412-417.

[12] D. M. Perez, G. S. Chang, D. M. Wachs, G. A. Roth and N. E. Woolstenhulme, "INL/EXT-12-27085. RERTR-12 Insertion 2 Irradiation Summary Report," Idaho National Laboratory, Idaho Falls, 2012.

[13] H. Ozaltun, H. Shen and P. Medvedev, "Assessment of residual stresses on U10Mo alloy based monolithic miniplates during Hot Isostatic Pressing," J. Nucl. Mater., vol. 419, no. 1-3, pp. 76-84, 2011.

[14] H. Ozaltun, R. M. Allen and Y. S. Han, "IMECE201366595: Effects of thickness of Zr-liner on stress-strain characteristics of U10Mo monolithic plates," in ASME IMECE2013, International Mechanical Engineering Congress \& Exposition, San Diego, CA, 2013.

[15] H. Ozaltun and P. Medvedev, "IMECE2014-36605: Effects of the foil flatness on the stress-strain characteristics of U10Mo monolithic mini-plates," in ASME IMECE2014, International Mechanical Engineering Congress \& Exposition, Montreal, CA, 2014.

[16] R. S. Barnes, "A Theory of swelling and gas release for reactor materials," J. of Nucl. Mater., vol. 11, no. 2, pp. 135-148, 1963.

[17] A. T. Churchman, R. S. Barnes and A. H. Cottrell, "Effects of Heat and Pressure on the Swelling of Irradiated Uranium," J.Nucl. Energy, vol. 7, no. 1-2, pp. 88-96, 1958.

[18] P. Medvedev and H. Ozaltun, "RRFM2014-A0101: Shutdown-induced tensile stress in monolithic miniplates as a possible cause of plate pillowing at very high burnup," in RRFM2014, Proceeding of Research Reactor Fuel Management of European Nuclear Society, Slovenia, 2014. 


\section{APPENDIX A}

Table A.1 Material properties for U10Mo

\begin{tabular}{|c|c|c|c|c|c|c|c|c|c|c|c|}
\hline \multicolumn{2}{|c|}{ Young's modulus } & \multicolumn{2}{|c|}{ Density } & \multicolumn{2}{|c|}{ Yield Stress } & \multicolumn{2}{|c|}{ Thermal expansion } & \multicolumn{2}{|c|}{ Thermal conductivity } & \multicolumn{2}{|c|}{ Specific heat } \\
\hline$\left[{ }^{\circ} \mathrm{C}\right]$ & {$[\mathrm{GPa}]$} & {$\left[{ }^{\circ} \mathrm{C}\right]$} & {$\left[\mathrm{kg} / \mathrm{m}^{3}\right]$} & {$\left[{ }^{\circ} \mathrm{C}\right]$} & [MPa] & {$\left[{ }^{\circ} \mathrm{C}\right]$} & {$\left[10^{-6 /} \mathrm{K}\right]$} & {$\left[{ }^{\circ} \mathrm{C}\right]$} & {$[\mathrm{W} / \mathrm{m} . \mathrm{K}]$} & {$\left[{ }^{\circ} \mathrm{C}\right]$} & {$[\mathrm{J} / \mathrm{kgK}]$} \\
\hline 21 & 87.27 & 25 & 17130 & 27 & 937 & 25 & 11.5 & 25 & 12.14 & 0 & 134.81 \\
\hline 200 & 73.54 & 100 & 17060 & 93 & 848 & 100 & 12.2 & 100 & 14.23 & 100 & 141.93 \\
\hline 400 & 51.97 & 200 & 16970 & 204 & 737 & 200 & 13.2 & 200 & 17.16 & 200 & 149.47 \\
\hline \multirow[t]{2}{*}{600} & 33.34 & 300 & 16880 & 316 & 634 & 300 & 14.2 & 300 & 20.09 & 300 & 157.00 \\
\hline & & 400 & 16800 & 427 & 531 & 400 & 15.2 & 400 & 23.02 & 400 & 164.54 \\
\hline \multicolumn{2}{|c|}{ Poisson's Ratio } & 500 & 16710 & 538 & 428 & 500 & 16.2 & 500 & 26.37 & 500 & 171.66 \\
\hline$\left[{ }^{\circ} \mathrm{C}\right]$ & {$[-]$} & 550 & 16660 & 593 & 373 & 600 & 16.6 & 600 & 30.14 & 600 & 179.19 \\
\hline \multirow[t]{2}{*}{25} & 0.324 & 600 & 16620 & & & 700 & 17.9 & 700 & 33.91 & 800 & 193.85 \\
\hline & & 700 & 16530 & & & 900 & 20.5 & 800 & 37.68 & 1000 & 208.92 \\
\hline
\end{tabular}

Table A.2 Material properties for Zr, Commercially pure, ASTM Grade 702

\begin{tabular}{|c|c|c|c|c|c|c|c|c|c|c|c|}
\hline \multicolumn{2}{|c|}{ Young's modulus } & \multicolumn{2}{|c|}{ Density } & \multicolumn{2}{|c|}{ Yield Stress } & \multicolumn{2}{|c|}{ Thermal expansion } & \multicolumn{2}{|c|}{ Thermal conductivity } & \multicolumn{2}{|c|}{ Specific heat } \\
\hline$\left[{ }^{\circ} \mathrm{C}\right]$ & {$[\mathrm{GPa}]$} & {$\left[{ }^{\circ} \mathrm{C}\right]$} & {$\left[\mathrm{kg} / \mathrm{m}^{3}\right]$} & {$\left[{ }^{\circ} \mathrm{C}\right]$} & {$[\mathrm{MPa}]$} & {$\left[{ }^{\circ} \mathrm{C}\right]$} & {$\left[10^{-6 /} \mathrm{K}\right]$} & {$\left[{ }^{\circ} \mathrm{C}\right]$} & {$[\mathrm{W} / \mathrm{mK}]$} & {$\left[{ }^{\circ} \mathrm{C}\right]$} & {$[\mathrm{J} / \mathrm{kgK}]$} \\
\hline 21 & 95.89 & 25 & 6499 & 21 & 314.70 & 21.00 & 5.841 & 21.00 & 23.11 & 21.00 & 293.3 \\
\hline 150 & 87.36 & & & 100 & 259.90 & 99.45 & 6.047 & 150.25 & 21.36 & 128.76 & 299.25 \\
\hline 205 & 83.68 & Pois & s Ratio & 149 & 204.00 & 148.05 & 6.178 & 344.55 & 20.58 & 226.37 & 305.16 \\
\hline 292 & 77.74 & [ $\left.{ }^{\circ} \mathrm{C}\right]$ & {$[-]$} & 197 & 146.80 & 196.75 & 6.279 & 521.95 & 21.18 & 278.05 & 308.12 \\
\hline 370 & 72.58 & 25 & 0.35 & 259 & 105.10 & 300.15 & 6.532 & 657.05 & 22.61 & 427.33 & 314.16 \\
\hline 426 & 68.71 & & & 297 & 92.62 & 349.85 & 6.653 & 798.85 & 24.02 & 576.61 & 320.19 \\
\hline 516 & 62.76 & & & 348 & 82.50 & 401.15 & 6.754 & 924.85 & 25.40 & 725.89 & 326.23 \\
\hline 611 & 56.40 & & & 400 & 75.95 & 450.15 & 6.876 & 998.85 & 26.16 & 806.28 & 357.67 \\
\hline
\end{tabular}

Table A.3 Minimum Creep rate for Grade 702 Zirconium alloy

\begin{tabular}{|c|c|c|c|c|c|c|c|c|c|}
\hline \multicolumn{2}{|c|}{$\mathrm{T}=21^{\circ} \mathrm{C}$} & \multicolumn{2}{|c|}{$\mathrm{T}=95^{\circ} \mathrm{C}$} & \multicolumn{2}{|c|}{$\mathrm{T}=205^{\circ} \mathrm{C}$} & \multicolumn{2}{|c|}{$\mathrm{T}=315^{\circ} \mathrm{C}$} & \multicolumn{2}{|c|}{$\mathrm{T}=370^{\circ} \mathrm{C}$} \\
\hline $\begin{array}{l}\text { Strain } \\
{[1 / \mathrm{h}]}\end{array}$ & $\begin{array}{l}\text { Stress } \\
{[\mathrm{MPa}]}\end{array}$ & $\begin{array}{l}\text { Strain } \\
{[1 / \mathrm{h}]}\end{array}$ & $\begin{array}{l}\text { Stress } \\
{[\mathrm{MPa}]}\end{array}$ & $\begin{array}{l}\text { Strain } \\
{[1 / \mathrm{h}]}\end{array}$ & $\begin{array}{l}\text { Stress } \\
{[\mathrm{MPa}]}\end{array}$ & $\begin{array}{c}\text { Strain } \\
{[1 / \mathrm{h}]}\end{array}$ & $\begin{array}{l}\text { Stress } \\
{[\mathrm{MPa}]}\end{array}$ & $\begin{array}{l}\text { Strain } \\
{[1 / \mathrm{h}]}\end{array}$ & $\begin{array}{l}\text { Stress } \\
{[\mathrm{MPa}]}\end{array}$ \\
\hline $2.878 \mathrm{E}-08$ & 119.50 & $2.090 \mathrm{E}-08$ & 88.22 & $1.401 \mathrm{E}-08$ & 54.86 & 2.949E-08 & 52.73 & $3.149 \mathrm{E}-08$ & 42.13 \\
\hline $4.464 \mathrm{E}-08$ & 134.57 & $4.521 \mathrm{E}-08$ & 106.12 & $2.088 \mathrm{E}-08$ & 60.97 & $4.453 \mathrm{E}-08$ & 57.83 & $4.510 \mathrm{E}-08$ & 46.21 \\
\hline $1.018 \mathrm{E}-07$ & 166.20 & $1.018 \mathrm{E}-07$ & 129.34 & $4.457 \mathrm{E}-08$ & 76.30 & $1.016 \mathrm{E}-07$ & 68.66 & $1.015 \mathrm{E}-07$ & 55.59 \\
\hline 2.173E-07 & 205.27 & 2.172E-07 & 155.59 & 1.017E-07 & 94.24 & 2.196E-07 & 80.43 & $2.195 \mathrm{E}-07$ & 65.13 \\
\hline 4.701E-07 & 253.52 & $4.697 \mathrm{E}-07$ & 189.64 & 2.199E-07 & 117.93 & 4.687E-07 & 94.24 & $4.684 \mathrm{E}-07$ & 75.30 \\
\hline $1.003 \mathrm{E}-06$ & 309.01 & $9.891 \mathrm{E}-07$ & 228.12 & 4.693E-07 & 143.75 & $1.000 \mathrm{E}-06$ & 110.40 & $9.996 \mathrm{E}-07$ & 88.22 \\
\hline $1.641 \mathrm{E}-06$ & 352.60 & $2.111 \mathrm{E}-06$ & 270.81 & $9.884 \mathrm{E}-07$ & 177.54 & $2.106 \mathrm{E}-06$ & 129.34 & $2.105 \mathrm{E}-06$ & 102.00 \\
\hline & & $3.642 \mathrm{E}-06$ & 309.01 & $2.110 \mathrm{E}-06$ & 219.27 & 4.495E-06 & 151.54 & & \\
\hline & & & & & & $9.721 \mathrm{E}-06$ & 175.21 & & \\
\hline & & & & & & $2.047 \mathrm{E}-05$ & 205.27 & & \\
\hline
\end{tabular}

Table A.4 Material properties for Al6061-O

\begin{tabular}{|c|c|c|c|c|c|c|c|c|c|c|c|}
\hline \multicolumn{2}{|c|}{$\begin{array}{l}\text { Young's } \\
\text { Modulus }\end{array}$} & \multicolumn{2}{|c|}{ Poisson's Ratio } & \multicolumn{2}{|c|}{ Yield Stress } & \multicolumn{2}{|c|}{$\begin{array}{c}\text { Thermal } \\
\text { Expansion }\end{array}$} & \multicolumn{2}{|c|}{ Conductivity } & \multicolumn{2}{|c|}{ Specific Heat } \\
\hline$\left[{ }^{\circ} \mathrm{C}\right]$ & {$[\mathrm{GPa}]$} & {$[\mathrm{C}]$} & {$[-]$} & {$[\mathrm{C}]$} & [MPa] & {$\left[{ }^{\circ} \mathrm{C}\right]$} & {$\left[10^{-6} 1 / \mathrm{K}\right]$} & {$[\mathrm{C}]$} & {$[\mathrm{W} / \mathrm{m}-\mathrm{K}]$} & {$[\mathrm{C}]$} & {$[\mathrm{J} / \mathrm{kg}-\mathrm{K}]$} \\
\hline 21 & 68.26 & 21 & 0.330 & 21 & 55.16 & 100 & 23.6 & 0 & 177 & 17 & 896 \\
\hline 100 & 65.50 & 100 & 0.334 & 205 & 55.16 & 200 & 24.3 & 77 & 186 & 127 & 942 \\
\hline 150 & 62.74 & 150 & 0.335 & 230 & 44.82 & 300 & 25.4 & 177 & 190 & 227 & 988 \\
\hline 177 & 61.36 & 177 & 0.336 & 260 & 37.92 & & nsity & 277 & 191 & 327 & 1034 \\
\hline 205 & 59.29 & 205 & 0.336 & 315 & 28.96 & {$[\mathrm{C}]$} & {$\left[\mathrm{kg} / \mathrm{m}^{3}\right]$} & 377 & 188 & 427 & 1080 \\
\hline 230 & 57.23 & 230 & 0.337 & 370 & 20.68 & 21 & 2690 & 477 & 182 & 527 & 1126 \\
\hline 260 & 54.47 & 260 & 0.338 & 425 & 15.17 & 93 & 2690 & 527 & 179 & 582 & 1151 \\
\hline 315 & 46.88 & 315 & 0.360 & 480 & 11.03 & 204 & 2660 & & & & \\
\hline 370 & 37.92 & 370 & 0.400 & 540 & 8.27 & 316 & 2630 & & & & \\
\hline
\end{tabular}




\section{APPENDIX A}

Table A.5 Thermal creep data for A16061-O

\begin{tabular}{ccccccc}
\hline Time & Strain & \multicolumn{5}{c}{ STRESS [MPa] } \\
\cline { 3 - 6 }$[\mathrm{h}]$ & {$[\%]$} & $177\left[{ }^{\circ} \mathrm{C}\right]$ & $205\left[{ }^{\circ} \mathrm{C}\right]$ & $260\left[{ }^{\circ} \mathrm{C}\right]$ & $315\left[{ }^{\circ} \mathrm{C}\right]$ & $370\left[{ }^{\circ} \mathrm{C}\right]$ \\
\hline 0.1 & 0.1 & 52.00 & 41.00 & 30.00 & 21.00 & 14.00 \\
0.1 & 0.2 & 55.00 & 45.00 & 31.00 & 22.00 & 15.00 \\
0.1 & 0.5 & 70.00 & 52.00 & 34.00 & 23.00 & 17.00 \\
0.1 & 1.0 & 75.00 & 55.00 & 38.00 & 25.00 & 17.00 \\
\hline 1 & 0.1 & 48.00 & 38.00 & 27.00 & 19.00 & 13.00 \\
1 & 0.2 & 52.00 & 41.00 & 28.00 & 20.00 & 14.00 \\
1 & 0.5 & 62.00 & 45.00 & 30.00 & 21.00 & 15.00 \\
1 & 1.0 & 70.00 & 48.00 & 32.00 & 22.00 & 16.00 \\
\hline 10 & 0.1 & 41.00 & 33.00 & 25.00 & 16.00 & 12.00 \\
10 & 0.2 & 45.00 & 34.00 & 26.00 & 18.00 & 12.00 \\
10 & 0.5 & 55.00 & 38.00 & 28.00 & 19.00 & 13.00 \\
10 & 1.0 & 62.00 & 41.00 & 30.00 & 20.00 & 14.00 \\
\hline 100 & 0.1 & 38.00 & 30.00 & 22.00 & 14.00 & 10.00 \\
100 & 0.2 & 41.00 & 32.00 & 23.00 & 15.00 & 11.00 \\
100 & 0.5 & 52.00 & 34.00 & 26.00 & 17.00 & 12.00 \\
100 & 1.0 & 59.00 & 38.00 & 27.00 & 18.00 & 12.00 \\
\hline 1000 & 0.1 & 38.00 & 28.00 & 20.00 & 12.00 & 9.00 \\
1000 & 0.2 & 41.00 & 30.00 & 21.00 & 13.00 & 10.00 \\
1000 & 0.5 & 48.00 & 31.00 & 23.00 & 14.00 & 10.00 \\
1000 & 1.0 & 55.00 & 32.00 & 23.00 & 15.00 & 11.00 \\
\hline
\end{tabular}

Table A.6 Yield Stress of AL6061-O with respect to fluence

\begin{tabular}{|c|c|c|c|}
\hline \multicolumn{2}{|c|}{$50^{\circ} \mathrm{C}$} & \multicolumn{2}{|c|}{$150^{\circ} \mathrm{C}$} \\
\hline $\begin{array}{c}\text { Fluence } \\
{\left[\mathrm{n} / \mathrm{m}^{2}\right]}\end{array}$ & $\begin{array}{c}\text { Yield } \\
\text { Stress } \\
{[\mathrm{MPa}]}\end{array}$ & $\begin{array}{c}\text { Fluence } \\
{\left[\mathrm{n} / \mathrm{m}^{2}\right]}\end{array}$ & $\begin{array}{c}\text { Yield Stress } \\
{[\mathrm{MPa}]}\end{array}$ \\
\hline $1.00 \mathrm{E}+25$ & 129.10 & $1.00 \mathrm{E}+25$ & 96.03 \\
\hline $4.60 \mathrm{E}+25$ & 162.77 & $4.60 \mathrm{E}+25$ & 127.55 \\
\hline $1.00 \mathrm{E}+26$ & 213.34 & $1.00 \mathrm{E}+26$ & 174.82 \\
\hline $9.60 \mathrm{E}+26$ & 292.26 & $1.00 \mathrm{E}+27$ & 250.18 \\
\hline $1.00 \mathrm{E}+27$ & 295.93 & & \\
\hline
\end{tabular}

Table A.7 Growth of A16061

\begin{tabular}{cc}
\hline \multicolumn{2}{c}{ Swelling due to Fluence } \\
\hline $\begin{array}{c}\text { Fluence } \\
{\left[\mathrm{n} / \mathrm{m}^{2}\right]}\end{array}$ & $\begin{array}{c}\text { Swelling } \\
{[\%]}\end{array}$ \\
\hline $1.82 \mathrm{E}+25$ & 0.01000 \\
$2.88 \mathrm{E}+26$ & 0.16746 \\
$1.83 \mathrm{E}+27$ & 2.02070 \\
\hline
\end{tabular}

